\title{
Bidrag til Skolevæsnets Historie i Hadersler Amt.
}

Af $N$. J. Andersen.

I Aaret 1650 modtoge Præsterne i Haderslev Amt en Slirivelse af følgenile Indhold:

Ffter vor Allernaadigste Herres og Konges Befaling bliver da denne nu udi nast forgangne Aar udi dette Len og Iy Haderslev anstillede og forordnede Gen. KirkeVisitation og derpaa folgende Kongelige Kommission at efterkomme - kundgjort:

a. Præsterne optegne de Sognefolk, som have Born; ville de ilkke lyde ng lade deres Børn soge Skole, da tilkendegives det for Ørigheden.

b. De maa Ingen til Herrens Bord antage eller kopulere, for de kunne forklare Luthers Katekismus og udsige deres Tros rette Mening.

c. Isyer, som ilke over 1/4 Mil ligge ude af Yejen, og hvor ingen farlige Veie med Aaer ere hinderlige, skulle skikke deres Born til Sogneskolemesteren.

d. Har Skolemesteren ingen visse eller altfor ringe Salaria, skal Folk alvorlig tilholdes at give ham noget vist, saasom en Gatardnand en Skjeppe Korn, en Kaadner, 3 til 4 Skilling. De Vægrende hor eksekveres og udpantes. 
e.f. Opbyrges ordentlige Skolehuse, og Prasten visitere Skolen hvert 4. Aar.

gr. Kirken skal betale for de fattige Børns Skolegang.

h.i. Hvert Sogn have sin Skole, og ikke bruges tyske Bøger paa danske Steder.

Haderslev, den 20. August 1650.
Kay v. Alllefeld.
D. Steph. Kilotz.

Nan fik imidlertid snart andet end Skolesager at tæuke paa. I de sidste 25 Aar havde Halvøen 2 Gange været overswommet af Fjender, først af de Kejserlige og dernæst af Srmnkerne, og lidt meget red Plyndring. Det var kum 5 Aar siden, den sidste Fred var bleven sluttet. 1657 ndbrod Krigen med Sverrig, der varede til Foraaret 1660. Først blev Halvøen indtaget af Svenskerne, men $1658 \mathrm{kom}$ en Hir paa 30,000 Mand bestaaende af Brandenborgere Wsterrigere og Polakker for at hjælpe os. Vel fordreve de, Svenskerne over til Øerne, men navnlig vare Polakkerne*) meget varre end Svenskerne. De gjorde sig skyldige i the værste Voldsomheder. I Moltrup afbrændte de Præstegaarden. Præsterne i Skodborg og Rodding bleve dræbte af dem. Byerne Slevad og Lilholt med Kapel bleve afbrændte. Strejfkorps flakkede omkring og plyndrede alle Vegne. Folk bleve hængte op i Skorstene i Røg. Man flygtede for dem ud i Skovene, og hvor man troede sig stærk nok dertil, skød man dem ned.

Samme Aar udbrod der Blodgrang, „den hvide Blodsot", ikke alene i Had. Amt, men ogsaa andet Sterls, f. E. i Jylland. Nange hundrede dode. Landet blev øide; Be-

*) Sammenlign: Polakkerne i Nordklesvir af J. Fausbsel: „Siund. Aarh." 18.15. 
boerne fattedes. I dette og forrige Aar kreperede, tænk, i dette Amt alene vist 28 Præstemænd*). 3 af Haderslev Latinskoles Lærere og 2 af Fruekirkens Præster dode af Sygdommen.

Da der var Brist paa Føde- og Sædekorn, steg Rugens Pris til 16 Daler, en umaadelig Pris efter daværende Forhold. - Der skulde Tid til at vinde Kræfter, inden der atter kunde tænkes paa Skolevæsnets Ordning.

Fra de følgende Tider er der opbevaret en Del Skrivelser om Skolevæsnet i Kirkearkivet i Hammeler. I den ældste Skrivelse fra 1719 fra Provst Fischer tales ikke alene om „en ordinær Degn og Skolemester" i Hammelev, men ogsaa om „alle andre Biskoler" i Sognet. 1731 byggede man en ny Skole i Styding. Efter en endnu opbevaret Regning kostede den 43 Daler 3 Skilling, men let ser ud til, at man enten har anfort en Cdwift forkert eller talt feil sammen; thi Summen af de anforte Poster bliver kun 38 Daler 3 Sk. Man havde købt 2700 Sten; Bygningen var som andre Bygninger den Til, Bindingsrærk og havde 6 Vinduer. Tomrer-, Snedker- og Murerlónnen var beregnet til 5 Daler; i denne Sum var dog ikke medregnet Vinduernes Pris. Tækkeren tik 1 Daler. Stydingerne ydede fri Haand- og Spændtjeneste red $\mathrm{O}^{\text {1- }}$ førelsen af Skoleluset.

Den 7. Dec. 1731 bade samtlige Indvaanere i Styding Provsten om efter Lofte af Kirkekassen at ville betale 5 M. 12 .Sk. til Mester Johannes Hansen for de 6 Vinduer i Skolehuset. Den 26. Febr. 1732 har Provsten skrevet paa Regningen, at foruden de nævnte 5 M. 12 Sk. skal

*) I'. Rhoile: Samlinger til Haderslev Amts Beskrivelse. 
Kirkekassen endridere udbetale 8 Daler 4 Sk. Maaske Nogen kunde synes, at det matte være en let Sag for' en hel By at udbetale den hele Sum, men til Belysning af den daværende Tilstand tillade vi os endnu engang at auføre, hvad Hr. P. Lauridsen*) før har anført i „S. Aarb.“ om Styding By: „Paa 18 storre og mindre Gaarde fimltes her 1724: 78 Heste og Føl, 74 Køer, 9 Stude, 55 Ungkvæy, 46 Kialve, 118 Faar, 49 Svin og Grise, 25 Gæs, 16 Plove og 30 Vogne, og ikke en Mand i hele Byen er fri for Skatterestancer; der for en enkelt endog lober langt op over 100 Ril. spec."

Skolehuset skulde baade afgive Skolestue og fri Bolig for Læreren. Om man nu fik en Lærer, paa bvem I. Rhodes Ord: „En dansk Skoleholder her er en Kunstner i Regnen og Skiven" kunde anvendes, kan være tvivlsomt nok. Den Slags Lærere fandtes vel nærmest i Købstæder og ved Degneskoler. Man vragede den Tid just ikke saa meget oy kunde heller ikke stille store Fordringer paa Grund af den lille Løn. Hvad det nu gjaldt om, var at far "en bestandig Skolemester".

1743 blev der af Pastor Prætorius i Hammelev efter Provstens Ordre skrevet folgende Skolekontrakt:

"I den H. Treenigheds Navn have vi underskrevne Lodsejere i Styding By til den store Guds Eres Forfremmelse og vores Ungdoms tilstrækkelige Underretning i deres liristendom velvillig og uden Trang os derhen forenet, og indtil vores naadigste Øvrigheds Approbation besluttet

1) at vi af yderste Formue ville med hinanden bestræbe os, at vorres Skolehus, som nu bruges, fremdeles altid maa conserveres i god Stand paa det at,

*) P. Lauridsen: „Sind. Aarb." 1891. 
2) i samme baade Vinter og Sommer kan lioldes er kristelig Skolemester og en bestandig Skole. Og paa det at Skolemesteren hos sit Arbeide og ma have sit Levnets Underhold, skulle

3) alle Børn, som findes imellem 5 og 8 Aar gaa baade Sommer og Vinter til Skole, mens fra 8 og til 12 Aar skulle de ikkun rære skyldige til at finde sig deriud om Vinteren. Dor er

4) ingenlunde Meningen denne, at med de benærnte Aar deres Skolegang enten om Sommeren eller om Vinteren pracis skulle ophore; thi Lnhver, som bar en kristlig Omsorg for sine Byrn, vil efter sin Erue vel af sig selv holde dem saa laenge til Skolen, som han ser, at de samme Steds tiltager og sig forbedrer. Mens

5) saadanne Skoleaar ere ikliun til den Ende determinerede, og ansutte, paa det at de Skødeslyse, som, Gud bedre det, ikke tage sig det ret til Hjerte med deres Borns kristlige Undervisning, des mere dertil maa blive opmuntrede, naar de, i de anforte Skoleaar, nemlig fra 5 ox til 8 baade Vinter og Sommer, og fra 8 og til 12 om Vinteren alene, skulle være pligtede til at betale de sælvanlige Skolepenge, hvad heller Bornene komme til Skole eller ej.

NB. Ogsaa om Nogen af Fortræolelighed vilde sende sine Børn i saadanne Aar til en fremmed Skole, skal han $\log$ betale Skolemesteren i Stydincr. Oy fordi Skolemesteren af saadanne Penge alene ikke kan leve, saa have vi af liristen Karlighed tilstaaet

6) af enhrer hel Gaard aurligen at give hannem til sin Underholdning 1 Skæppe Rug og dexforuden

7) paa Byens Kogang at holde hannem een Koes Grxs. 
aarligen fri, hvoraf han skal have sin Nytte, enten lan selv lohller en Ko eller ej. Derimorl skal den, som Skolen anbetroes i Styding by,

8) blive bestandig baade Vinter og Sommer, udlen at gøre efter sin egen Behag Fridage, hos Bornenes Information og for alle Ting se derhen, at de ma undervises $i$ Guds og vor Frelsers Kundskab og anfores til Guds Frygt og alle kristelige Dyder. Hrorudi han og selv skal gaa dem fore med sit egret gode Eksempel.

9) skal han være skyldig at straffe de Genstridiges Ondskab paa en tillorlig Maade uden derudi af Foraldrene at forlindres, og

10) skal han udlove og forpligte sig til at sta Sognedegnen bi udi hans Emberlets Forretning, saa vel i som uden Kirken. Dơ ikke videre end naar Notlen det udkræver, og Degnen saalant af hannem begærer.

Som vi nu visseligen haaber, at vi paa saalan Maade kunne faa en rel indrettet Skole og en bestandig Skolemester, saa indfalde vi til vorres Hojbydende $\mathrm{Hr}$. $\mathrm{Hr}$. Visitatores med underdanig og ydmyg Bøn og Begroring, at de denne vorres gjorde Forslag ikke alene ville approbere men og naadigst confirmere, paa det samme altid og uryggelig maatte blive staaendis. Hvorved vi dog med allerdybeste Lnderdanighed undtager Hans Kongl. Maystt. allernaadigste Villie og Befaling, om det enten over kort eller lang Tid maatte behage allerhojstbemeldte Ilans Maystt. herudi at gón'e en allornaadigste Forandring eller at forsoge en almindelig Skolernes Forbcdring: Hrilket da og vi paa den Fald med allerunderdanigste Lydighed skulle vide at venerere". - Herefter folger et Tillag, der just ikke hgrer med til Skolekontrakten, men er en Hen- 
vendelse til Stydingerne. Det lyder saaledes: "Herhos kunde man efter mit Tykke underdanigst bede, at $\emptyset_{\text {vrigheden }}$ dette saaledes vilde confirmere, at de samtlige Styding Mænd selv uden derom at overløbe deres Øvighed mante anholde de Fortrædelige til at afdrage deres Skyldighed enten med at tage tilstrækkelig Pant fra dem, eller deslige som vorres naadigste $H$. $H$. Visitatores efter deres berlste Tykke kunde forføje.

Jeg haver paa hans Højærværdigheds Provstens Ordre vildet meddele Eder dette Forslag, paa det de Vedkommende herover maatte gøre Aftale med hverandre om de saadant, som det er forfattet, ville antage; eller om dem synes, at noget herudi kunde forandres og forbedres, hrorpaa jeg da og med det Første forventer Eders Resolution.

Ellers kan jeg være Eder god derfor, at dette Eders samtykkede fri Vilkaar ikke af 2 eller 3 Genstridige og Fortrædelige skal omstødes. Og beder til Beslutning kærligen, at $\dot{I}$ tillige ville forenbare Eder derover og samtlig beslutte, at efterdags i Skolehuset ikke skal holdes Grande, paa det at ikke derover kommer mere Klagemaal.

Hammelev, d. 7. Jan. 1743.

\section{Prætorius."}

Denne Skolekontrakt maa imidlertid ikke have fundet megen Yndest i Styding; thi den blev kun underskrevet af 8 Stydinger, altsaa af Mindretallet. Bedre Lykke havde en ny „Skole-Convention“ i Aaret 1758. Den lyder saaledes :

„Saasom vi samtl. underskrevne Lodsejere af Styding til vores og Ungdommens store Skade har mattet fornemme, hvorledes vi hidindtil ikke har kunnet komme til retskaftien vores Skole istand at sætte, saa læenge vi leve uden Vedtregt, 
dette nøje (i) Betragtning tagen, og til Ungdommens mærkelige Opbyggelse, have vi efter andre omliggende Byers Eksempel paa vores IIøjgunstige Øvigheds og Hans Hojærværdigheds H. Provstes naadige og gunstige Approbation i Dag underskreven dato med hverandre og med god Raad og Villie indgaaet, frembaaret og sluttet efterfølgende Skole-Convention:

1) skal hver Gaardmand, det være sig hel, halv, fjerde eller ottendelspart Gaard, som haver Børn fra 5 og til 10 Aar, være forbunden $0 \mathrm{~g}$ forpligtet til at koste og lonne Skolemesteren Vinteren og Sommeren;

2) som og de Børn, der er over 10 Aar, skal den, som Børnene tilhører, koste og lønne Skolemesteren om Vinteren alene;

3) hvortil alle Gaardenes Besiddere skal og være forbunden og forpligtet til at de, som ingen Børn have eller og de, som have ikke skolevoksne Børn, at give af hver hel Gaard 16 Sk., en halv dito 8, en Fijerdeparts Gaard 4 Sk. og saa fort til Skolemesterens Løn, nemlig i 2le Terminer, Halvpart om Paaske og Resten om Mikeli, eller nar som Skolelønnen bliver samlet, tillige et af Landbolerne 4 Skilling om Aaret;

4) hvad Skolehuset er angaaende, det være sig med Reparation, eller og et nyt skulde oprettes, skal ske efter Gaarde-Tal, at enhver Gaard efter advinan kan tilkomme at give Materialer eller Onkostninger lige meget, det maa være hvad Narn, det være kan, at forskaffe og vedligeholde.

Enclelig for det 5te: Dersom Nogen herefterdags forser sig noget mod Skolen, som Kontrakten ellers kunde være imod, skal han erlægge til Skolens Reparation 8 Skilling 
ng til H. Kongl. Maystt. Bøler første Ganı 16 Sk. Irvorved Kontrahenterne for sig og deres Efterkommere alle optankelige Eksemptioner eller Udflugter, som herimod kunde rorde optrenkt eller i Fremtiden optænkes, samt alt ulen Svig og Argelist, ved Tro, Hader, Ere og gode Love fast ubrydeligen skal holde og efterkomme. Til Stadfæstelse have vi nærværende SkoleKonvention velvitterligen $o g$ egenhandig underskrevet, og H. Horjvelbaarenhed Herr Kammerherre or Amtmand i Haderslev samt tillige H. Højærværdighed Herr Provst

i Haderslev underdanigst og tjenestl. omberlet, at de til Vitterlighed madig og gunstig ville belage merl os at subskribere og rathihabere.

Actum Styding d. 30. Okt. Anno 1758.

Kontrakten er underskreven af 20 stydinger, hroraf 5 med fort Haand; Fjerdeparten har altsaa ikke kunnet skrive deres eget Navn.

Underneden er endnu tilfojet, at Landbolerne kun skulde betale 2 Sk."aarlig. Bemærkningen er undertegnet af Peter Matzen.

Allerede 1731 havde der været Nogle, der ikke havde villet betale til den nye Skole. Trods Skole-Konventionen var der endnu en hel Del i Vejen. Allerede i Marts 1759 indsendte 11 Stydinger en Klage imod "de Crenstridige" til Kirkevisitatoriet. Klagen lyder saaledes:

„Ellers Hoj- og Velb. saavel som Eders Hojarwærdighed noles vi underskrevne af lıøjnøltrængende Aarsag til i dybeste Underdanighed og Idmyghed at forestille rores Anliggende, da det er at befrygte, at udi rol By (hvor der er en temmelig stor Del af Born, som nodrendig Sommer og Vinter af en forstandig, klistelig og tro Skole- 
mester burde at anfores til det Gode, livilket de fleste af Forældrene i Byen ogsaa hjerteligen sinsker), saasnart Skolemesteren om Paasketiden afgaar, ingen Skole mere bliver holden, og Ungdommen derover, istedetfor at lære noget Godt, maa faa Lejlighed til at fordrive den æulle Tid paa Gaden, og formedelst Vanartigheds Øvelse forglemme Alt, hvad de tilforne haver lert, og de yngre Born, som efterhaanden snart kunde medtages til Skolen, aldeles maatte blive forsomt, livilket og visseligen sker, hvis ikke Deres Hoj- og Velb. som ogsaa Hojærværdighed i Henseende til Guds Ałre og Ungdommens sande Velfard naadig og hrijgunstigr anbefaler enhver udi Byen alvorligen, at de ulen Modsigelse skal vare pligtige at give deres Andel saavel til Skolemesterens Underhold og Belonning som til Skolehusets Reparation. Vel haver vi underskrerne tilligemed Sognepræsten givet al mulig Flid dertil, men de Genstridige, til livilke ikke alene cle Faa, som ingen Born haver, men ogsaa $i$ visse Marier nogle af dem, som da Gud har velsignet dermed, kan henresnes, haver altid givet Forhindring derudi, saa at det nu er kommen til Fuldkonmenhed. Beder derfor i dybeste Underdanighed og Idmyghed Deres Hoj-og Velb. og Deres Højæerværdighed naarig og hojgunstig vilde behage derhen at decretere, at samtlige Lodsejere saavelsom Landbolerne og hvem, som haver Born skal være skylden or tilholden at lade deres Born antegne til Skole fra 7 Aar og indtil 14, dernæst at enhver af Lorlsejerne, enten de have Børn eller ej, dor efter deres Gaaripart maa vare plintige at yde deres Andel, Oy da det, som vi alt tilforn underdanig or ylmygelig haver anfort, er en temnelis stor By og mange Lurn deruli, som nodvendig behøver en god Skoleholder, 
at der da maatte benærnes en visse Sum til en duelig Skolemesters Belonning, som kan vorde fordelt paa den hele By til Enhver i Særdeleshed efter Omstændighederne, at paa saadan Maade os samtl. af vores Naadige og Højgunstige Ørrighed et bestandigt Forhold med Skolen maa vorde foreskreven, hvorefter vi uden nogen Modsigelse og Tvistighed stedse kan vide at rette os.

Vi forvente paa demne rores kristelige Ansøguing en Nialig og Hryjgunstig Bønhøring og forbliver stedse

Eders Høj- og Velbaarenheds

som ogsaa

Eders Hojærværdigheds underdanigste og ydmygeste Tjenere (Derefter folge de 11 Navne.)

Auf Verlangen der Mehrsten aus dem Dorfe Styding habe mit unterthäniger und gehorsamster Bitte, dasz die Ilindernis wegen einer beständigen Schule auf einmal möge gehoben werden, dieses zu unterschreiben ich nicht unterlassen können.

Hammelev, d. 19. Mïrz 1759.

C. Prætorius.

Fra Amtmand Klingenberg kom der da d. 23. April 1759 den Befaling, at ovenfor nærnte 11 saa rel som de, der ikke vilde vedkende sig den af de fleste Stydinger undertegnede Overenskomst, havde at møde paa Amtshuset den 1. Maj Kl. 10. Her kom man da til gensidig Forstaaelse.

Imidlertid saae det ikke bedre ud i de 2 andre Sholedistrikter. I en Indberetning vistnok fra $\mathbf{1 7 6 0}$ hedder det i Oversattelse:

„Hvad der redrører de to Biskoler, saa har jeg dog 
Gud være lovet, efter stor Naje havt den Lykke, at det er kommen i Orden med Skolen i Styding, hvilket er sket paa det Kongl. Amthus. Med Skolen i Gl.-Ladegaard er det ligeledes kommen til en lykkelig Afslutning jaa det Kongl. Amthus. - Men med Kirkeskolen ser jeg allerede forud, at der vil være endnu større Vanskelighed og vel slet ikke vil kunne komme i Stand uden Tvangsmidler. Foruden mig er der kun 3 Mænd som betale med Penge; de andre komme ham til Hjælp med lidt Pløjning, Bortforelse af Gøduing og Kørsel, hrorved man da har slaaet sig til Ro."

Der fandtes intet Skolehns i Hammelev, men Degnen holdt Skole i sit eget Hus; han ejede nemlig et Kong. Landbol, livis Skatter bleve betalte af Skoledistriktet. Selv betalte han Skolestuens Reparation. Der blev ikke holdt Skole fra St. Hansdag til Mikkelsdag. Naar der blev talt med Forældrene derom, svarede de: „Vi ere ikke i Stand til at holde Tjenestetyende. Ved Arbeidet trænge vi til saa mange af vore Børn, som liunne arbejde." - „De Smaa, som ikke kunne Andet, vogte om Sommeren Gæs og Svin." - I Byen var der 40 Sholebørn.

Den 4. Febr. 1762 have samtlige Lodsejere af Gl.Ladegaard og Jernhyt forenet sig om en Skole-Konvention. Bormene skulle gaa i Skole fra 6-10 Aar baade Vinter og Sommer, men fra 10-14 Aar kun om Vinteren; Forxllrene skulle koste og lonme Læreren; de Forældre, som ikke have Børn, skulle aarlig give ham $12 \mathrm{Sk}$. af hrer hel Gaard; de, som have flere end 2 skolepligtige Børn, og koste Liereren, skulle give ham $1 / 2$ Sk. lybsk hver 6 Dage, hvorimod de, der ikke koste ham, skulle give en hel. Hvert Landbol skal halvaarig give 2 Sk. - 
Den 16. April 1766 er der indgatet en ny Orerenskomst, hvorefter de $12 \mathrm{sk}$. ere llevne forhrjede til 1 Mark lybsk; alle, enten de have Burm eller ej, skulle koste Lareren, paa en hel Gaard dobbelt saa længe som paa en halv, og paa en halv dobbelt saa længe som paa et Landbol. Børmenes Forældre skulle skaffe Ildebrændsel.

Ogsaa fra Ladegaard blev der 1767 indgivet en Klage til Kirkevisitatoriet over, at en Halvgaardejer og en Landbolsmand i $L$. ikke vilile rette sig efter Skole-Kontrakten, ng at Jernhytterne efterfulgte deres Eksempel. Der siges, at Lareren kostes 8 Dage paa hver hel Gaard, 4 paa hver halv Gaard og 2 par et Landbol. Kirkevisitatorerne befaler d. 12. Maj 1767 de Anklagede at tiltræde Orerenskomsten inden 3 Dage.

I Juli 1778 klager Lareren over, at han den Somner kun har havt ligjst 6 eller 7 Børn i Skole, ja de fleste Dage kun 1, 2 eller 3, nogle Dage ingen. Fra Jernhyt havde der ingen været i Skole siden Paaske. Han skriver blandt Andet: „Jeg har for en 5 Aars Tid udbedet ved det hoje naadige Amtshus et Dekret paa de naklixsige Forældre at paalægge mel daglig Eksekution 2 Sk. for hvert Barus Udeblivelse. Samme høje Dekret lod jeg forelæese for samtl. Vedkommende. - Jeg efter samme naadige Befaling forholdt mig et Par Aars Tid med Eksekution paa de forsømmelige Forældre; saa befandt, jeg, at Skoleinteressenterne fik Fjendskab til mig, for jeg vilde, at deres Børn skulde folge Skolen."

Læreren var altsaa her en Slags Herredsfoged! Han fortaller endvidere, at Dekretet blev ham frastjaalet. Denne, "Skoleholder Todsen", havde 1785 kun 24 Daler i Sloolclon forudon 2 Daler, som han fik af Kirkekassen 
3 Aar derefter var han, da han rar en gammel Mand, ikke langere Lærer og fik da 8 Daler af Fattigkassen.

1768 bleve Skoledistrikterne Hammelev og Styding slatede sammen til et, og der blev bygget en fælles Skole lidt Nord for Stærningen. Desuden skulde ogsaa Konfirmanderne fra Ladegaard og Jernhyt besoge Degneskolen. Lærerens Indtægter bleve $3 \mathrm{Tdr}$. Rug, 3 Tdr. Malt, $1 \mathrm{Tdr}$. Byg eller Boghvede, Land til 2 Köer og 5 Faar, 3 Læs Ho, 2 Læs Halm og 12 Læs 'Træ eller Tørr. Skolelønnen var 8 Sk. aarlig pr. Barn. 1808 blev Degnens Skolelon forhyjet til 40 Daler, og et Aar derefter bleve de 3 Læs Ho formulret til 6 Læs ì 600 Pund.

1846 bleve begge Skoledistrikter igen adskilte, idet baade Hammelev og Styding da fik nye Skoler. Enkelte Havevakster vidne endnu om, hvor den gamle Degneskole har staiet. 